\title{
CARACTERIZAÇÃO DA INDÚSTRIA LÍTICA DO SÍTIO LAPA GRANDE DE TAQUARAÇU,
}

MG

\author{
Maria Ester Venezia ${ }^{i}$
}

Astolfo G. M. Araujoii

i Doutoranda do Museu de Arqueologia e Etnologia (MAE) da Universidade de São Paulo USP

ii Docente do Museu de Arqueologia e Etnologia (MAE) da Universidade de São Paulo USP

Resumo: O sítio arqueológico Lapa Grande de Taquaraçu é um abrigo sob rocha localizado no município de Taquaraçu de Minas, MG. Sua indústria lítica foi manufaturada majoritariamente a partir de cristais de quartzo com o objetivo de produzir lascas. Os artefatos apresentam a tendência de terem atributos métricos reduzidos. Estas características seguem o padrão encontrado em outros sítios de Lagoa Santa. Palavras-chave: indústria lítica, análise quantitativa, Lapa Grande Taquaraçu, Lagoa Santa.

Abstract: The archaeological site Lapa Grande de Taquaraçu is a rock shelter located in the municipality of Taquaraçu de Minas, MG. Its lithic industry was mostly manufactured from quartz crystals in order to produce flakes. Artifacts tend to show reduced metric attributes. These characteristics follow the pattern found in other Lagoa Santa sites. Keywords: lithic industry, quantitative analysis, Lapa Grande Taquaraçu, Lagoa Santa. 


\section{Introdução}

As pesquisas arqueológicas na região de Lagoa Santa tiveram início no final do século XIX, com os estudos efetuados por Peter Lund ${ }^{1}$. Além dos trabalhos de Lund, também podemos destacar as pesquisas realizadas por equipes do Museu Nacional do Rio de Janeiro (1920-1930), os estudos realizados durante mais de 20 anos pela Academia de Ciências de Minas Gerais, as campanhas internacionais Americano-Brasileira, com os trabalhos de Wesley Hurt e Oldemar Blasi (década de 1950) e a Missão Franco-Brasileira (década de 1970) com a descoberta do crânio de "Luzia", realizada por Laming-Emperaire (vide Da-Gloria et al 2017 para uma revisão histórica), e posteriormente por sua análise e datação direta através das pesquisas de Walter Neves na década de 1990, obtendo-se a idade mínima de 9 mil anos (Feathers et al., 2010).

Trabalhos arqueológicos mais recentes foram desenvolvidos pelo Laboratório de Estudos Evolutivos Humanos do Instituto de Biologia da Universidade de São Paulo (LEEH- IB/USP), com o projeto "Origens e Microevolução do Homem na América: uma abordagem Paleoantropológica" (Araujo e Neves, 2012).

Os primeiros sítios a serem pesquisados no âmbito desse projeto foram a Lapa das Boleiras, Lapa da Cerca Grande VI e Lapa do Santo. Em 2003 foi iniciada a pesquisa no sítio Lapa Grande de Taquaraçu- nosso objeto de pesquisa - e em anos subsequentes, outros sítios arqueológicos foram adicionados ao projeto (Araujo et al., 2012). Dentre os resultados obtidos nas pesquisas, pode-se destacar basicamente que a ocupação humana de Lagoa Santa ocorreu por volta de 8.000 a 12.000 anos AP, mais intensamente em cavernas e abrigos, e a subsistência dos grupos tinha como base a coleta de tubérculos, frutas e sementes, sendo complementada através da caça de pequenos mamíferos e da pesca, não havendo evidência de que tais habitantes ocupavam-se da caça de megafauna; mesmo comprovando a coexistência com algumas espécies (Kipnis et al., 1998; Nakamura et al., 2010; Prous et al., 1998).

A indústria lítica de Lagoa Santa, em sua maioria produzida em quartzo e com tamanho reduzido (em média $22 \mathrm{~mm}$ de dimensão máxima), apresenta poucas peças retocadas (menos de 1\%) e poucas formas definidas (Moreno de Sousa e Araujo, 2018), com raras ocorrências de pontas

\footnotetext{
${ }^{1} \mathrm{O}$ dinamarquês Peter Lund foi pioneiro nas explorações e no estudo sistemático das cavernas de Lagoa Santa a partir de 1840 , projetando a região no mundo científico através de sua hipótese de contemporaneidade entre as populações pré-históricas "Homem de Lagoa Santa" - e a fauna pleistocênica extinta (Holten; Sterll, 2011; Prous et al.,1998).
} 
bifaciais, estas sem cronologia definida (Lapa do Eucalipto, Lapa da Limeira e Lapa das Carrancas - Araujo et al, 2012; Araujo e Pugliese, 2010).

Além dos líticos lascados, peças polidas de rochas ígneas e metamórficas também eram produzidas e utilizadas no Holoceno Inicial (Araujo et al, 2012) na forma de lâminas de machado com diferentes graus de polimento e lascamento; uma das mais antigas evidências de polimento na América (Bueno, 2012; Moreno de Sousa e Araujo 2018).

É importante observar que a indústria lítica produzida pela população paleoíndia de Lagoa Santa difere da manufaturada por grupos indígenas modernos (Araujo et al, 2012), além do fato de ser também "distinta das indústrias líticas existentes em outras regiões do Brasil Central durante o Holoceno Inicial" (Araujo e Pugliese, 2010), conforme supracitado.

De acordo com Araujo e colaboradores (2012), todos os sítios paleoíndios dessa região apresentaram até o presente indústrias líticas similares, e no caso dos abrigos sob rocha, "essa similaridade se estende a artefatos ósseos, práticas de enterramento e subsistência" (op. cit.: p. 541).

Dados obtidos através de pesquisas em Lagoa Santa e em outras regiões da América do Sul sugerem que a ocupação Paleoíndia se iniciou de forma abrupta há aproximadamente 11700 anos cal AP, sendo observada através de culturas materiais totalmente distintas, principalmente em relação aos vestígios líticos (Araujo, 2013; 2015).

Dentro desse contexto, o estudo do material lítico da Lapa Grande de Taquaraçu é imprescindível para uma comparação com os outros abrigos na área central do carste (Lapa das Boleiras e Lapa do Santo) e assim estabelecer se de fato ele pode ser inserido dentro da "Tradição Lagoa Santa" (descrita por Moreno de Sousa e Araujo 2018), levando em conta que o abrigo está localizado em uma área limítrofe, já fora do carste, mais próxima à Serra do Espinhaço, a leste.

\section{Características do sítio Lapa Grande de Taquaraçu}

O sítio Lapa Grande de Taquaraçu (UTM 23K 632619 / 7831528), está situado no município de Taquaraçu de Minas - MG, uma cidade predominantemente rural com aproximadamente 3.800 habitantes, localizada a aproximadamente $60 \mathrm{~km}$ de distância da capital Belo Horizonte e a 20 km da APA de Lagoa Santa. (IBGE, 2017) (Figura 1). Trata-se de um abrigo sob rocha, com $30 \mathrm{~m}$ 
de extensão e abertura para oeste, $9 \mathrm{~m}$ de largura máxima e altura de $7 \mathrm{~m}$ em relação à margem esquerda do rio Taquaraçu (Angeles Flores, 2015; Araujo, 2012.; Araujo at al., 2012) (Figura 2).

O sítio está inserido na Província São Francisco, no Complexo Belo Horizonte ao sopé da Serra da Piedade entre a Formação Serra de Santa Helena e a Formação Sete Lagoas, Membro Pedro Leopoldo, ambas pertencentes ao Grupo Bambuí, apresentando predominantemente rochas calcárias, gnáissicas e graníticas (Alkmin e Martins Neto 2001).

Os sedimentos do sítio Taquaraçu são basicamente antropogênicos, em sua quase totalidade de cinzas de madeira (Silva e Prous 2014), apresentando também uma pequena contribuição de depósitos geogênicos de silte e argila proveniente do rio adjacente (Tudela 2013).

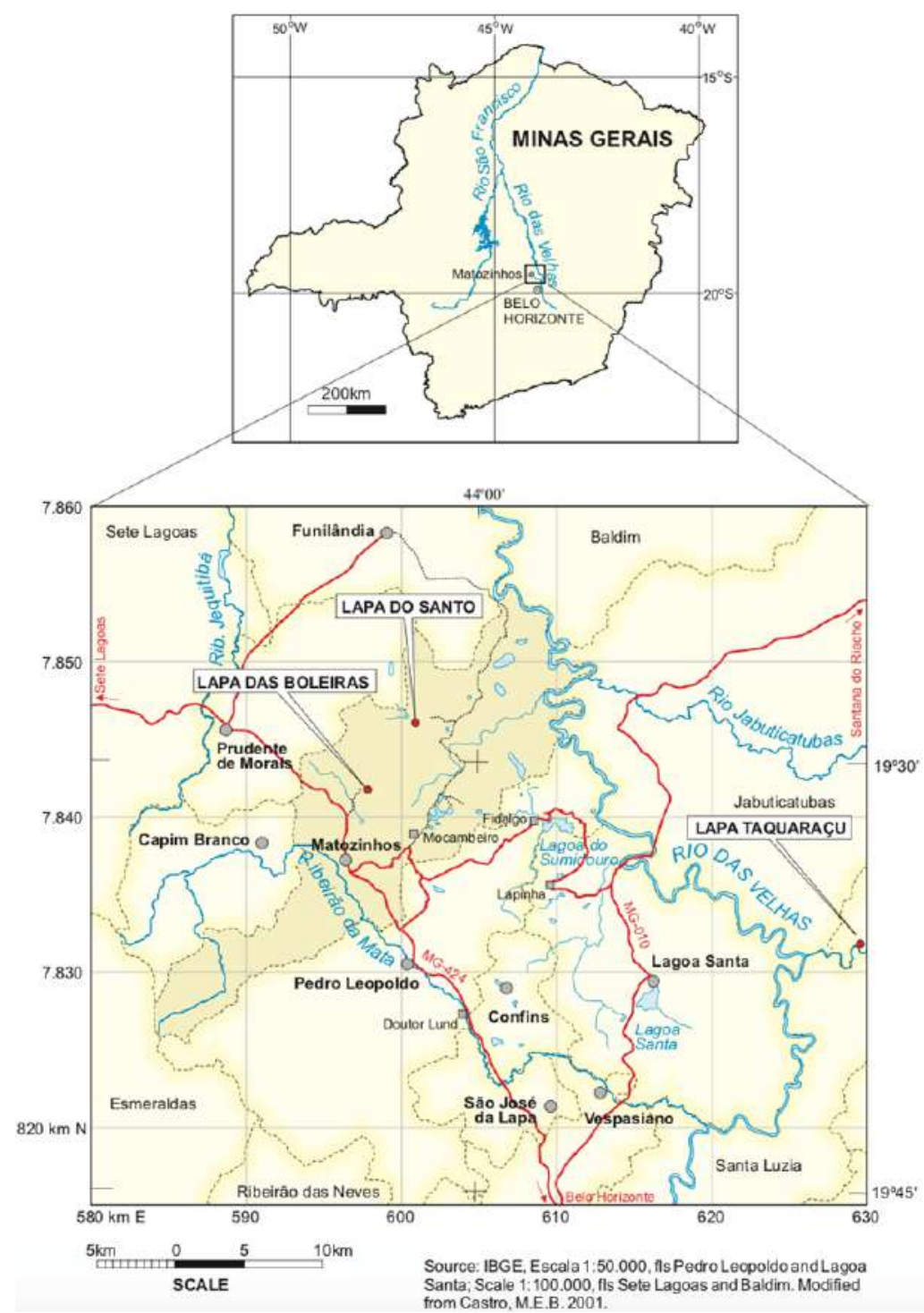

Figura 1: Localização geográfica do sítio Lapa Grande de Taquaraçu com destaque para os sítios Lapa do Santo e Lapa das Boleiras na APA Lagoa Santa. Fonte: Araujo et al. (2018). 


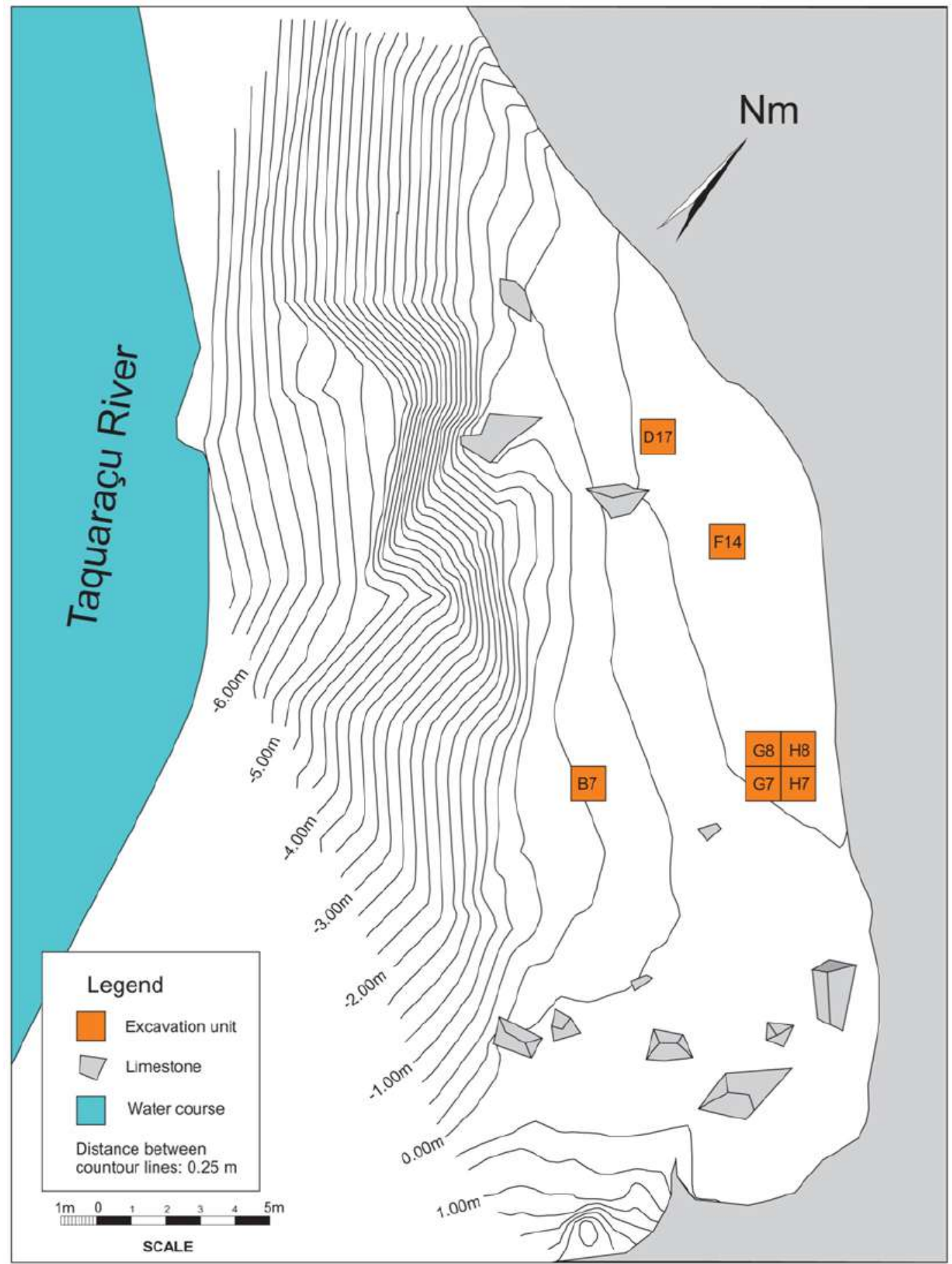

Figura 2: Topografia e localização das quadras escavadas no Sítio Lapa Grande de Taquaraçu. (Fonte: Angeles Flores et al, 2016).

No sítio Lapa Grande de Taquaraçu houve um total de cinco campanhas de trabalho intensivo de campo, que ocorreram anualmente entre 2003 e 2008 (Araujo, 2012). 
Os métodos de campo adotados seguiram um protocolo com estratégia mista, que teve como base escavações de unidades básicas $1 \times 1 \mathrm{~m}$, plotagem individual de peças, coleta sistemática, peneiramento e registro fotográfico. A técnica de escavação adotada considerou "o rebaixamento das fácies de maneira individual, já que tanto a plotagem de peças quanto a coleta de amostras e o peneiramento foi realizado por fácies." Assim, como solução foi adotado o rebaixamento das fácies com no máximo $5 \mathrm{~cm}$ de profundidade. (Araujo, 2012) (Figura 3).

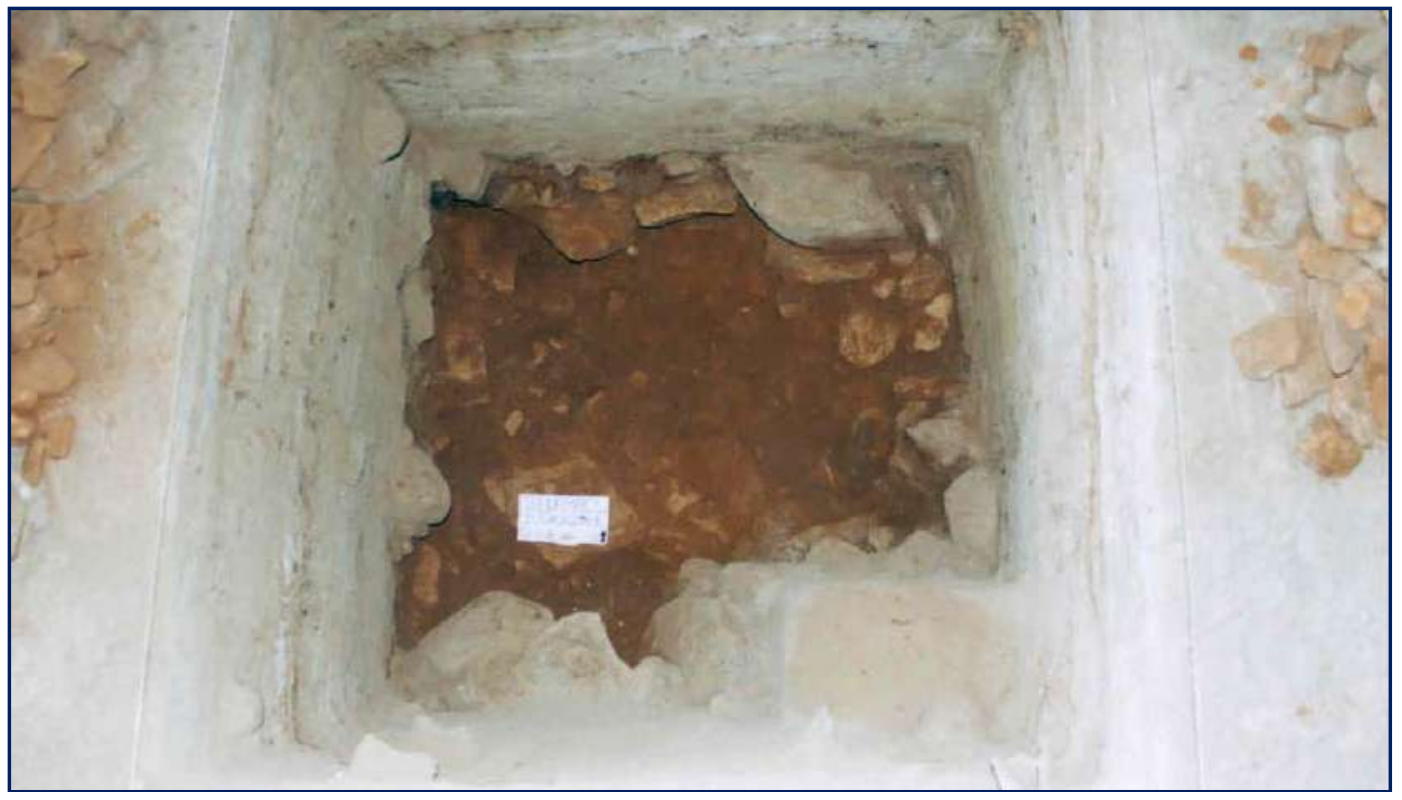

Figura 3: Escavação da Quadra G evidenciando as características do pacote sedimentar do sítio Lapa Grande de Taquaraçu (Fonte: Araujo, 2012).

Como resultado, observou-se que a estratigrafia do sítio possui profundidade máxima de $1 \mathrm{~m}$, e evidenciado pacote arqueológico de $80 \mathrm{~cm}$ de espessura, contendo uma grande quantidade de vestígios líticos, faunísticos e cerâmicos, além de ossos humanos pertencentes a dois indivíduos - um jovem e um bebê (Angeles-Flores, 2015; Araujo et al., 2012).

O sedimento do sítio Taquaraçu - conforme já citado - é basicamente antropogênico, composto por cinzas (Araujo, 2008). Datações por ${ }^{14} \mathrm{C}$ indicaram que a ocupação no sítio ocorreu no período paleoíndio ${ }^{2}$ entre 9990 +/- 60AP e 8080 +/- 40 anos AP - em datas não calibradas -, com um hiato entre 8.000 e 1.100 AP (Holoceno Médio - Figuras 4 e 5) (Angeles-Flores, 2015).

\footnotetext{
2 O termo "Paleoíndio" é utilizado com diferentes significados. Nos Estados Unidos e no Canadá, por exemplo, é normalmente aplicado ao modo de vida caçador-coletor e/ou à manufatura de grandes pontas bifaciais. No Brasil, o termo é relacionado a fatores cronológicos, ou seja, refere-se a populações que existiram entre 12.900 e 8.300 cal. AP, ou entre 11.000 e 8000 anos AP $\left({ }^{14} \mathrm{C}\right)$ (Araujo, 2015).
} 


\begin{tabular}{lcccc}
\hline Sample number & Level & Facies & $\begin{array}{c}\text { Radiocarbon date } \\
\text { (Years BP) }\end{array}$ & $\begin{array}{c}\text { Calibrated date } \\
\text { (Years BP) }\end{array}$ \\
\hline TQ 421 & 1 & 2 & $1160 \pm 60$ & $1087 \pm 78$ \\
TQ 417 & 1 & 3 & $8080 \pm 40$ & $9028 \pm 41$ \\
TQ 402 & E Profile & $X$ & $8230 \pm 50$ & $9202 \pm 82$ \\
TQ 430 & 3 & 9 & $8310 \pm 40$ & $9344 \pm 59$ \\
TQ 441 & 4 & 11 & $8730 \pm 40$ & $9703 \pm 82$ \\
TQ 404 & E Profile & $X$ & $8730 \pm 50$ & $9720 \pm 102$ \\
TQ 454 & 5 & 11 & $8910 \pm 40$ & $10052 \pm 96$ \\
TQ 459 & 6 & $X$ & $9040 \pm 40$ & $10218 \pm 17$ \\
TQ 297 & 7 & $X$ & $9540 \pm 90$ & $10896 \pm 164$ \\
TQ268 & 8 & $X$ & $9550 \pm 60$ & $10911 \pm 139$ \\
TQ295 & 6 & $X$ & $9620 \pm 40$ & $10979 \pm 131$ \\
TQ 536 & 9 & 19 & $9990 \pm 60$ & $11477 \pm 133$ \\
TQ 544 & 10 & 20 & $9900 \pm 60$ & $11349 \pm 89$ \\
\hline
\end{tabular}

Figura 4: Tabela de datas calibradas do sítio Taquaraçu. Fonte: Angeles-Flores et al. (2015)

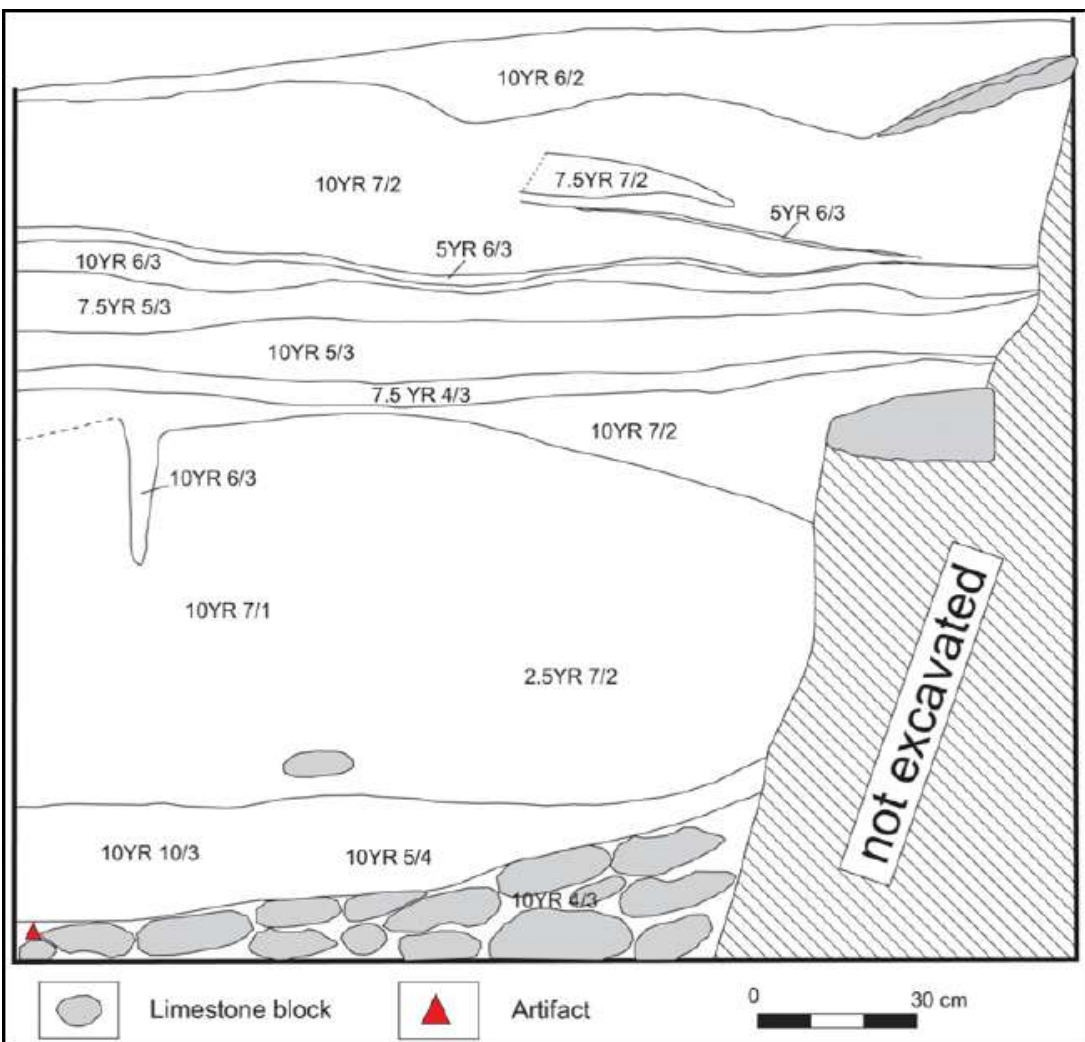

Figura 5: Estratigrafia do Sítio Taquaraçu. Fonte: Angeles-Flores et al. (2016)

\section{Caracterização Geral da Indústria lítica do sítio Lapa Grande de Taquaraçu}

Durante as campanhas de escavação realizadas no sítio Lapa Grande de Taquaraçu, foram evidenciadas e registradas 2974 peças líticas e ósseas (Araujo, 2012).

Todos os artefatos líticos do sítio Taquaraçu aqui analisados foram coletados durante as campanhas de escavação já citadas. O sistema de classificação empregado seguiu o exposto em 
Araujo e Pugliese (2010) para a Lapa das Boleiras com pequenas modificações, permitindo a comparação futura entre sítios.

O total de peças líticas analisadas é de 1879, englobando todas as quadras escavadas.

\section{Matéria-prima}

Conforme pode-se observar na Tabela 1 e no Gráfico 1, 86\% da matéria-prima do sítio é composta por quartzo em geral (1616 peças), sendo a maior parte de quartzo hialino (64.66\%). O segundo tipo de material mais abundante encontrado foi silexito (9.15\%), seguido de quartzito (1.76\%) e arenito silicificado (1.70\%).

Tabela 1: Frequência de composição de matéria-prima

\begin{tabular}{|c|c|c|}
\hline Matéria-prima & Quantidade & $\%$ \\
\hline Quartzo & 55 & 2.93 \\
\hline Quartzo hialino & 1215 & 64.66 \\
\hline Quartzo leitoso & 346 & 18.41 \\
\hline Arenito silicificado & 32 & 1.70 \\
\hline Basalto & 8 & 0.43 \\
\hline Granito & 1 & 0.05 \\
\hline Silexito & 172 & 9.15 \\
\hline Outras & 17 & 0.90 \\
\hline Quartzito & 33 & 1.76 \\
\hline Total & 1879 & 100.00 \\
\hline
\end{tabular}

Gráfico 1: Frequência de composição de matéria-prima no sítio Taquaraçu.






\section{Tipo de Suporte}

Analisando-se o Tabela 2 e o Gráfico 2, é possível notar que a maior parte dos artefatos líticos de quartzo hialino encontrados no sítio Taquaraçu são oriundos de cristais, sendo estes presentes em $51.30 \%$ das peças analisadas. O segundo tipo de suporte mais frequente no sítio são os blocos de quartzo leitoso (8.52\%) - o que reforça a imensa prevalência na preferência dos cristais de quartzo para manufatura dos artefatos do sítio comparados aos demais suportes e matérias-primas.

Gráfico 2: Taquaraçu - Frequência de suporte x principais matérias-primas.

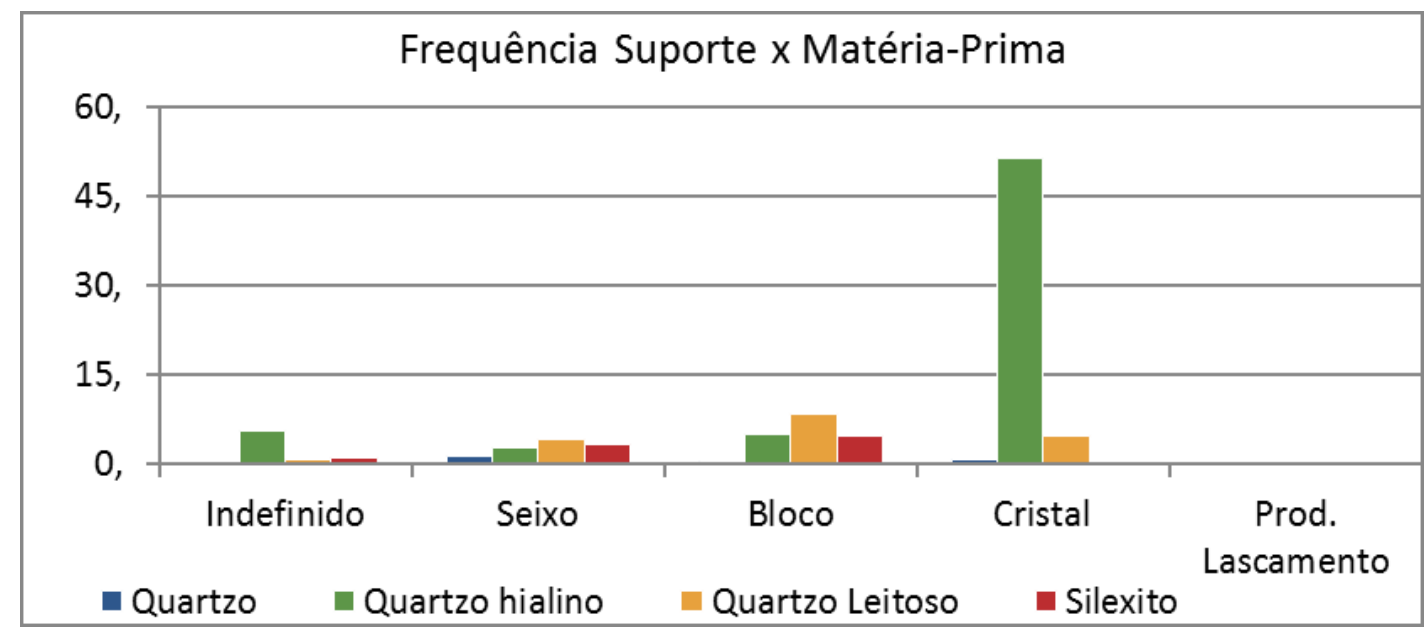

Tabela 2: Taquaraçu - Frequência de suporte x principais matérias-primas.

\begin{tabular}{|c|c|c|c|c|}
\hline $\begin{array}{l}\text { Suporte/Mat. } \\
\text { Prima }\end{array}$ & Quartzo & Quartzo hialino & Quartzo Leitoso & Silexito \\
\hline Indefinido & 0.05 & 5.53 & 0.90 & 0.96 \\
\hline Seixo & 1.49 & 2.66 & 4.15 & 3.35 \\
\hline Bloco & 0.64 & 4.90 & 8.52 & 4.79 \\
\hline Cristal & 0.75 & 51.30 & 4.79 & 0 \\
\hline Prod. Lascamento & 0 & 0.21 & 0.05 & 0 \\
\hline
\end{tabular}

\section{Classes de Materiais}

Os dados referentes à frequência das peças analisadas do sítio Lapa Grande de Taquaraçu, de acordo com a sua classificação, estão dispostos no Tabela 3 e no Gráfico 3: 
Tabela 3: Taquaraçu - frequência de tipos de artefatos.

\begin{tabular}{|c|c|c|}
\hline Rótulo & Quantidade & $\%$ \\
\hline Lasca & 1109 & 59.02 \\
\hline Estilha & 107 & 5.69 \\
\hline Fragmento de lasca & 131 & 6.97 \\
\hline Frag lasca retocada & 1 & 0.05 \\
\hline frag lasca utilizada & 18 & 0.96 \\
\hline Lâmina & 1 & 0.05 \\
\hline Lasca espatifamento & 2 & 0.11 \\
\hline Lasca fragmentada & 31 & 1.65 \\
\hline Lasca retocada & 14 & 0.75 \\
\hline Lasca utilizada & 173 & 9.21 \\
\hline Lasca utilizada frag & 4 & 0.21 \\
\hline Matéria-prima bruta & 72 & 3.83 \\
\hline Material Polido & 0 & 0.00 \\
\hline Núcleo & 112 & 5.96 \\
\hline Núcleo utilizado & 3 & 0.16 \\
\hline Percutor & 13 & 0.69 \\
\hline Resíduo & 86 & 4.58 \\
\hline Seixo lascado & 2 & 0.11 \\
\hline Total & 1879 & 100 \\
\hline
\end{tabular}

Gráfico 3: Taquaraçu - frequência de tipos de artefatos.

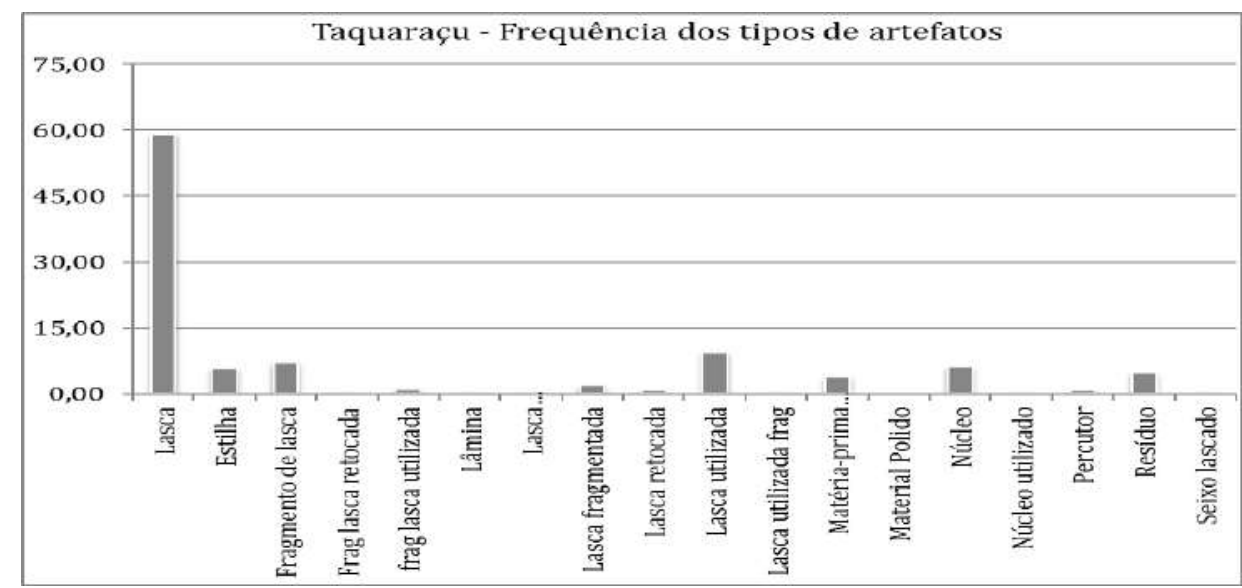

Como pode ser observado no Tabela e no gráfico acima, a maior parte da indústria lítica do sítio Lapa Grande de Taquaraçu é composta por lascas inteiras (59.02\%), seguidas de lascas utilizadas (9.21\%), fragmentos de lasca (6.97\%) e núcleos (5,96\%). 


\section{Características Gerais dos artefatos}

Núcleos

Os núcleos, de maneira geral, representam $6.12 \%$ da amostra de artefatos líticos do sítio Lapa Grande de Taquaraçu. Neste estudo, os núcleos foram divididos entre Núcleos não-Utilizados e Núcleos Utilizados.

Núcleos não Utilizados (NNU)

Os núcleos não utilizados correspondem a 5.96\% ( $n=112)$, e são compostos em sua maioria por quartzo hialino, seguido de quartzo leitoso, quartzo e silexito (Gráfico 4):

Gráfico 4: Taquaraçu - frequência de matérias-prima entre os núcleos não-utilizados.

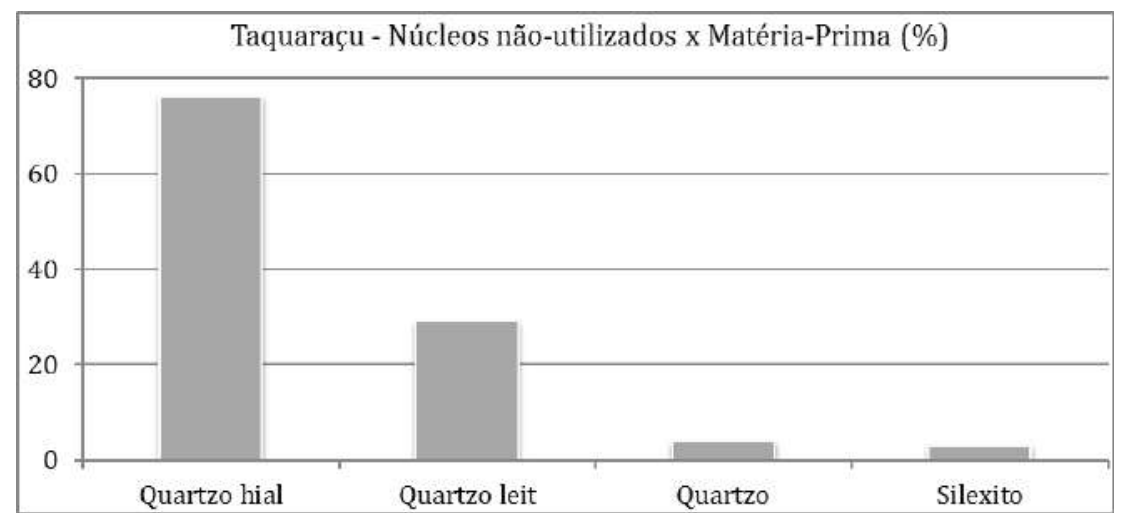

No gráfico acima se observa que a indústria lítica do sítio Lapa Grande de Taquaraçu a matériaprima mais frequente é o quartzo hialino (68.93\%), seguida de quartzo leitoso, quartzo e finalmente silexito.

Os dados gerais das dimensões desses núcleos podem ser conferidos na Tabela 4 a seguir:

Tabela 4: Taquaraçu - Dados de dimensões dos núcleos não-utilizados.-1

\begin{tabular}{|l|c|c|c|c|}
\hline \multicolumn{1}{|c|}{ Núcleo } & Comprim $(\mathbf{m m})$ & Largura $(\mathbf{m m})$ & Espessura $(\mathbf{m m})$ & Peso $(\mathbf{g})$ \\
\hline Mínimo & 8.00 & 9.00 & 5.00 & 1.30 \\
\hline Minimo quartil & 17.00 & 15.00 & 5.00 & 1.50 \\
\hline Mediana & 22.00 & 20.00 & 8.00 & 3.50 \\
\hline Máx. quartil & 29.00 & 26.00 & 12.00 & 7.80 \\
\hline Máximo & 74.00 & 62.00 & 37.00 & 129.50 \\
\hline
\end{tabular}

Analisando-se os dados contidos na Tabela 4 observa-se que os comprimentos mínimo e máximo são de 8 e 74 mm respectivamente. A largura apresenta dimensões mínima e máxima de 9 e 62 
$\mathrm{mm}$ e ao dados de espessura mínima e máxima são 5 e $37 \mathrm{~mm}$ respectivamente. 0 peso dos núcleos não-utilizados variam entre 1,3 e 129,5 g, sendo os núcleos mais pesados sempre de maior tamanho.

Gráfico 5: Taquaraçu - Dados gerais de grandeza dos núcleos não-utilizados.

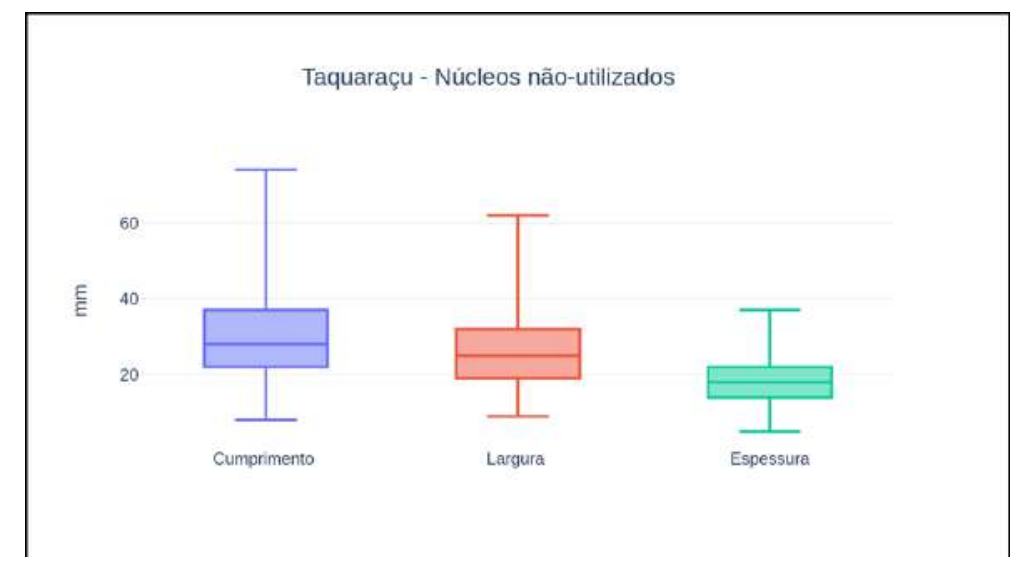

O Gráfico 5 demonstra a tendência de os núcleos apresentarem dimensões reduzidas, o que é corroborado pelo fato de os quartis estarem mais próximos dos valores mínimos do que dos máximos e pela ligeira assimetria positiva na linha mediana de grande parte das dimensões apresentadas.

Núcleos Utilizados (NU)

O material analisado apresentou apenas 3 (três) núcleos utilizados no sítio Lapa Grande de Taquaraçu - todos em quartzo hialino - correspondendo a $0.16 \%$ da amostra. Assim, decidiu-se demonstrar os dados relacionados aos mesmos na Tabela 5.

Tabela 5: Taquaraçu - Dados de grandeza dos núcleos utilizados.

\begin{tabular}{|l|c|c|c|c|}
\hline \multicolumn{1}{|c|}{ Núcleo } & Comprim $(\mathbf{m m})$ & Largura $(\mathbf{m m})$ & Espessura $(\mathbf{m m})$ & Peso $(\mathbf{g})$ \\
\hline Mínimo & 24.00 & 19.00 & 9.00 & 5.90 \\
\hline Minimo quartil & 17.00 & 15.00 & 6.00 & 1.70 \\
\hline Mediana & 21.50 & 20.00 & 9.00 & 4.15 \\
\hline Máx. quartil & 28.75 & 26.00 & 14.00 & 8.15 \\
\hline Máximo & 26.00 & 29.00 & 19.00 & 21.60 \\
\hline
\end{tabular}

A Tabela 5 sugere que os núcleos utilizados do sítio Lapa Grande de Taquaraçu possuem dimensões muito próximas às dos não utilizados. Porém, tendo em vista o tamanho reduzido da amostra, torna-se impossível afirmar isso com certeza. É possível que, dada a característica 
simples da indústria, a escolha de peças para serem utilizadas se desse por questões muito simples de tamanho e presença de gumes adequados à tarefa imediata.

Lascas

Consultando a Tabela 3, é possível observar que 78.93\% dos artefatos encontrados no sítio Lapa Grande de Taquaraçu é composto de lascas (inteiras e fragmentadas).

As lascas do sítio Lapa Grande de Taquaraçu são, em geral, oriundas majoritariamente de quartzo hialino (869 peças - $65,43 \%$ ), seguido de quartzo leitoso, conforme se pode observar no Gráfico 6, abaixo:

Gráfico 6: Taquaraçu - quantidade de lascas x matéria-prima



$\mathrm{Na}$ análise a seguir, serão expostos os resultados de análises das dimensões das lascas respeitando as subdivisões classificatórias adotadas na presente pesquisa.

Lascas não-utilizadas:

As lascas inteiras não-utilizadas representam $59,02 \%$ da amostra, e os dados obtidos para suas dimensões são:

Tabela 6: Taquaraçu - Métricas das lascas inteiras não utilizadas.

\begin{tabular}{|l|c|c|c|c|}
\hline \multicolumn{1}{|c|}{ Lasca } & Comprim $(\mathbf{m m})$ & Largura $(\mathbf{m m})$ & Espessura $(\mathbf{m m})$ & Peso $(\mathbf{g})$ \\
\hline Comp mínimo & 4.00 & 4.00 & 1.00 & 0.50 \\
\hline Mínimo quartil & 17.00 & 4.00 & 1.00 & 0.10 \\
\hline Mediana & 22.00 & 20.00 & 8.00 & 3.50 \\
\hline Máx. quartil & 29.00 & 26.00 & 12.00 & 7.80 \\
\hline Comp máximo & 73.00 & 73.00 & 65.00 & 104.40 \\
\hline
\end{tabular}


Conforme é possível observar, as lascas do sítio Lapa Grande de Taquaraçu possuem comprimento máximo de $70 \mathrm{~mm}$, largura máxima de $73 \mathrm{~mm}$ e espessura máxima de $65 \mathrm{~mm}$.

Também nota-se que os dados dimensionais das lascas deste sítio são simétricos, estando o centro de distribuição dos dados (medianas) localizados na região central de $50 \%$ dos valores dos conjuntos de dados; o que quer dizer que não há muita variação nos dados. Na prática, isso significa que há um padrão nas dimensões das lascas do sítio Lapa Grande de Taquaraçu. Notase, além disso, que $50 \%$ dos dados dimensionais das lascas se encontram mais próximos dos mínimos, o que frisa o fato de que as lascas possuem tendência a apresentarem dimensões reduzidas.

Em relação ao peso, o valor mínimo apresentado no Tabela 6 é de 0,50 g e o máximo 104,40 g e a mediana é de 3,50 g. Diante desses dados, e observando o Gráfico 7, é possível notar que há uma enorme tendência de lascas com peso próximo dos valores mais baixos, assim como também se observa que os dados são positivamente assimétricos.

Gráfico 7: Taquaraçu - Dados gerais de grandeza das lascas inteiras não-utilizadas.

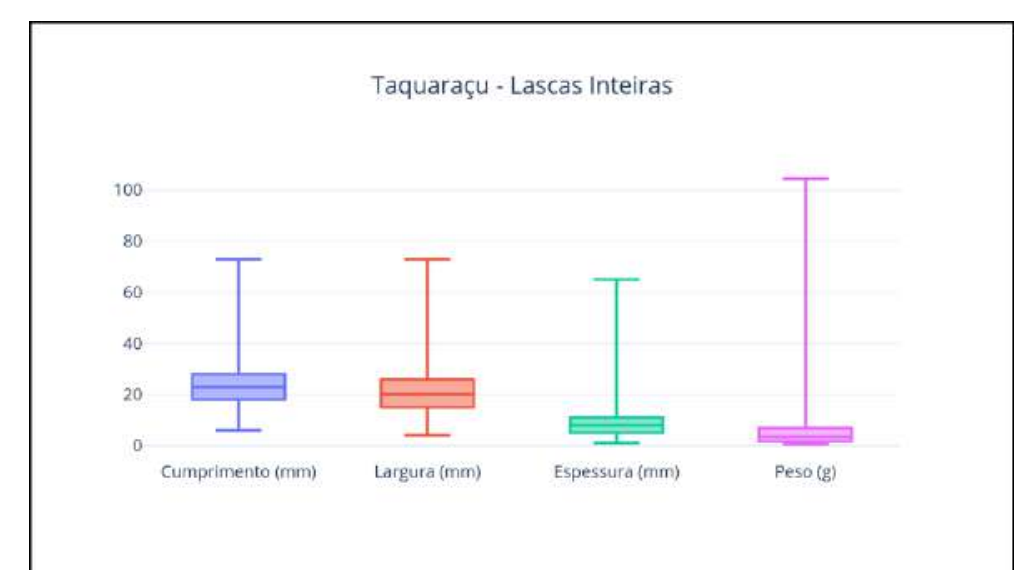

Lascas Utilizadas

Quanto às lascas utilizadas do sítio Lapa Grande de Taquaraçu, a Tabela 7 evidencia que as mesmas variam em comprimento entre $4 \mathrm{~mm}$ e $70 \mathrm{~mm}$, em largura entre 5 e $58 \mathrm{~mm}$ e espessura entre 2 e $65 \mathrm{~mm}$. O peso mínimo varia desde $0,5 \mathrm{~g}$ a $85 \mathrm{~g}$. É interessante notar que o conjunto de dados que englobam as dimensões das lascas utilizadas são parecidos com os das lascas inteiras (Tabela 6). Isso sugere que a decisão de se utilizar uma lasca aparentemente não se dava pelo tamanho. 
No Gráfico 8 é possível observar que no caso das lascas utilizadas, os dados dimensionais são positivamente assimétricos e apresentam tendência a se aproximar dos valores mínimos; novamente demonstrando o tamanho reduzido das peças.

Tabela 7: Taquaraçu - Dados dimensionais das lascas utilizadas.

\begin{tabular}{|l|c|c|c|c|}
\hline Lasca Utilizada & Comprim. $(\mathbf{m m})$ & Largura $(\mathbf{m m})$ & Espessura $(\mathbf{m m})$ & Peso (g) \\
\hline Mínimo & 4.00 & 5.00 & 2.00 & 0.5 \\
\hline Mínimo quartil & 17.00 & 15.00 & 5.00 & 1.50 \\
\hline Mediana & 22.00 & 20.00 & 8.00 & 3.50 \\
\hline Máx. quartil & 29.00 & 26.00 & 12.00 & 7.80 \\
\hline Máximo & 70.00 & 58.00 & 65.00 & 85.00 \\
\hline
\end{tabular}

Gráfico 8: Taquaraçu - Dados gerais de grandeza das lascas utilizadas.



Fragmentos de lascas

De acordo os resultados observados na Tabela 8 e no Gráfico 9, apesar de não serem inteiros, os fragmentos de lasca possuem comprimento e largura mínimos maiores que as lascas inteiras ( $5 \mathrm{~mm}$ e $7 \mathrm{~mm}$ respectivamente), porém o mesmo não acontece com os dados métricos máximos e de peso - que são menores - e com as medianas, que possuem valores iguais ou parecidos. É possível que este resultado seja relacionado a fatores tafonômicos, especialmente pisoteamento, que tenderia a fazer com que lascas com dimensões muito superiores a $7 \mathrm{~mm}$ acabassem por se fragmentar.

Assim como nas lascas utilizadas, os dados de comprimento, espessura e peso dos fragmentos de lasca são positivamente assimétricos, caracterizando novamente a tendência de se aproximarem de valores mínimos. 
Tabela 8: Taquaraçu - Dados de grandeza dos fragmentos de lascas.

\begin{tabular}{|l|c|c|c|c|}
\hline Fragm. de lasca & Comprim $(\mathbf{m m})$ & Largura $(\mathbf{m m})$ & Espessura $(\mathbf{m m})$ & Peso $(\mathbf{g})$ \\
\hline Mínimo & 5.00 & 7.00 & 2.00 & 0.1 \\
\hline Minimo quartil & 17.00 & 15.00 & 5.00 & 1.50 \\
\hline Mediana & 22.00 & 20.00 & 8.00 & 3.50 \\
\hline Máx. quartil & 29.00 & 26.00 & 12.00 & 7.80 \\
\hline Máximo & 58.00 & 52.00 & 21.00 & 41.8 \\
\hline
\end{tabular}

Gráfico 9: Taquaraçu - Dados dimensionais dos fragmentos de lascas.

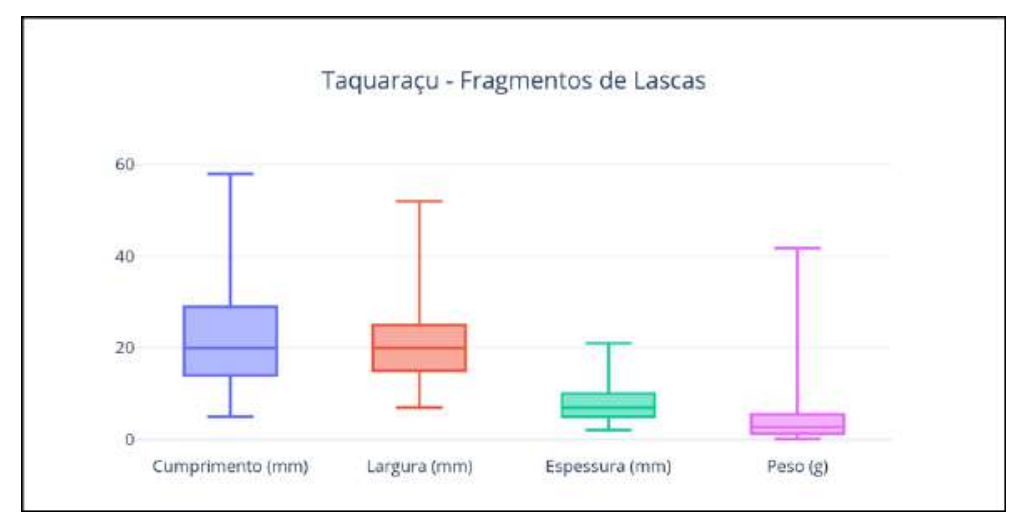

Fragmentos de Lascas Utilizadas:

Em relação aos fragmentos de lascas utilizadas $(n=18)$ do sítio Lapa Grande de Taquaraçu, podese observar na Tabela 9 e no Gráfico 10 que estes tendem a apresentar dimensões maiores do que todos os conjuntos de dados relativos a lascas apresentados até aqui. Porém estes aparecem com frequência muito menor $(0,96 \%)$ comparados às lascas utilizadas inteiras $(9,21 \%)$, o que indica que a incidência desses fragmentos maiores não é ocasionada por preferência em obter lascas maiores, mas pela ocasional disponibilidade núcleos com dimensões maiores.

Isso pode ser corroborado pelo fato de o dado de comprimento apresentar acentuada assimetria positiva; ou seja, há uma grande tendência do comprimento dessas peças apresentar tamanhos menores.

Adicionalmente, ao observar o banco de dados, duas peças maiores se destacam das demais: Tq426, cuja matéria prima é o quartzito e possuem dimensões 70 × 59 × 19 mm, e Tq1442, manufaturado em arenito silicificado com dimensões $53 \times 37 \times 14 \mathrm{~mm}$. No entanto, as demais peças apresentam cumprimentos no mínimo $22 \mathrm{~mm}$ menores e são de quartzo hialino, quartzo 
leitoso ou silexito, o que também confirma a presença de fragmentos maiores devido à simples e eventual disponibilidade de núcleos maiores.

Tabela 9: Taquaraçu - Dados de grandeza dos fragmentos de lascas utilizadas.

\begin{tabular}{|l|c|c|c|c|}
\hline Fragm. lasc. util. & Comprim $(\mathbf{m m})$ & Largura & Espessura & Peso \\
\hline Mínimo & 13.00 & 9.00 & 3.00 & 0.70 \\
\hline Minimo quartil & 17.00 & 14.00 & 5.00 & 1.50 \\
\hline Mediana & 22.00 & 20.00 & 8.00 & 3.40 \\
\hline Máx. quartil & 28.00 & 26.00 & 12.00 & 7.80 \\
\hline Máximo & 70.00 & 59.00 & 19.00 & 58.90 \\
\hline
\end{tabular}

Gráfico 10: Taquaraçu - Dados dimensionais dos fragmentos de lascas utilizadas.

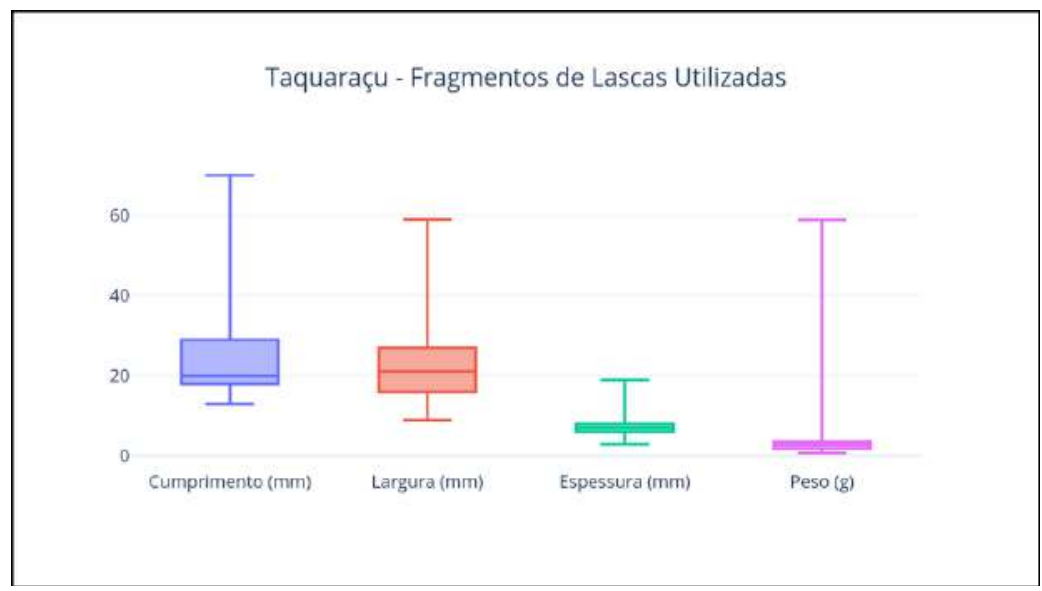

Lascas Fragmentadas

As lascas fragmentadas ( $n=31$ ) compreendem $1.65 \%$ da amostra analisada do sítio Lapa Grande de Taquaraçu e suas dimensões estão apresentadas a seguir na Tabela 10 e no Gráfico 11.

O comprimento das lascas fragmentadas varia entre 7 e $69 \mathrm{~mm}$, a largura entre 9 e $47 \mathrm{~mm}$ e a espessura está entre 2 e $32 \mathrm{~mm}$. O peso varia entre 0,30 e 118,70 g. É importante observar no Gráfico 11 que mais uma vez, a tendência entre todas as grandezas é de apresentar valores próximos dos mínimos, ou seja, apenas algumas peças possuem dimensões e peso maiores.

Tabela 10: Taquaraçu - Dados gerais de grandeza das Lascas Fragmentadas.

\begin{tabular}{|l|c|c|c|c|}
\hline \multicolumn{1}{|c|}{ Lasca Fragm. } & Comprimento & Largura & Espessura & Peso \\
\hline Mínimo & 7.00 & 9.00 & 2.00 & 0.30 \\
\hline Mínimo quartil & 17.00 & 15.00 & 5.00 & 1.50 \\
\hline Mediana & 22.00 & 20.00 & 8.00 & 3.50 \\
\hline Máx. quartil & 29.00 & 26.00 & 12.00 & 7.80 \\
\hline Máximo & 69.00 & 47.00 & 32.00 & 118.70 \\
\hline
\end{tabular}


Gráfico 11: Taquaraçu - Dados gerais de grandeza das Lascas Fragmentadas.

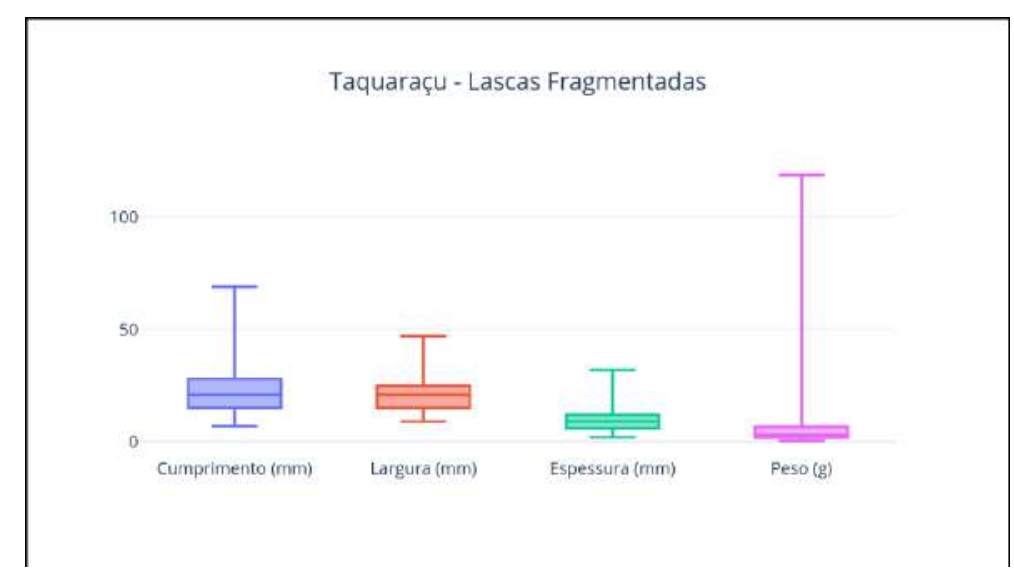

\section{Percutores}

Os percutores do sítio Lapa Grande de Taquaraçu representam apenas 0.69\% da amostra, com apenas 13 peças, todas tendo seixos como suporte.

A maior parte dos percutores do sítio Taquaraçu é constituída de quartzo leitoso (46.15\%), seguido de quartzo hialino e quartzo (ambos com 23.08\%).

Em relação às dimensões, os percutores do sítio Lapa Grande de Taquaraçu variam em comprimento de 22 a $62 \mathrm{~mm}$, em largura de 17 a $69 \mathrm{~mm}$, em espessura de 10 a $54 \mathrm{~mm}$ e em peso, de 6.70 a $327.10 \mathrm{~g}$ (Tabela 11).

Analisando-se o Gráfico 12, nota-se que os atributos comprimento e largura dos percutores do sítio Lapa Grande de Taquaraçu possuem valores aproximados e as espessuras são menores. Isso se dá porque muitos destes percutores possuem forma arredondada, porém achatada nas faces superior e inferior.

Tabela 11: Taquaraçu - Dados gerais de grandeza dos Percurores.

\begin{tabular}{|l|c|c|c|c|}
\hline \multicolumn{1}{|c|}{ Percutores } & Comprimento & Largura & Espessura & Peso \\
\hline Mínimo & 22.00 & 17.00 & 10.00 & 6.70 \\
\hline Minimo quartil & 17.00 & 15.00 & 5.00 & 1.50 \\
\hline Mediana & 22.00 & 20.00 & 8.00 & 3.50 \\
\hline Máx. quartil & 29.00 & 26.00 & 12.00 & 7.80 \\
\hline Máximo & 62.00 & 69.00 & 54.00 & 327.10 \\
\hline
\end{tabular}


Gráfico 12: Taquaraçu - Dados gerais de grandeza dos Percurores.

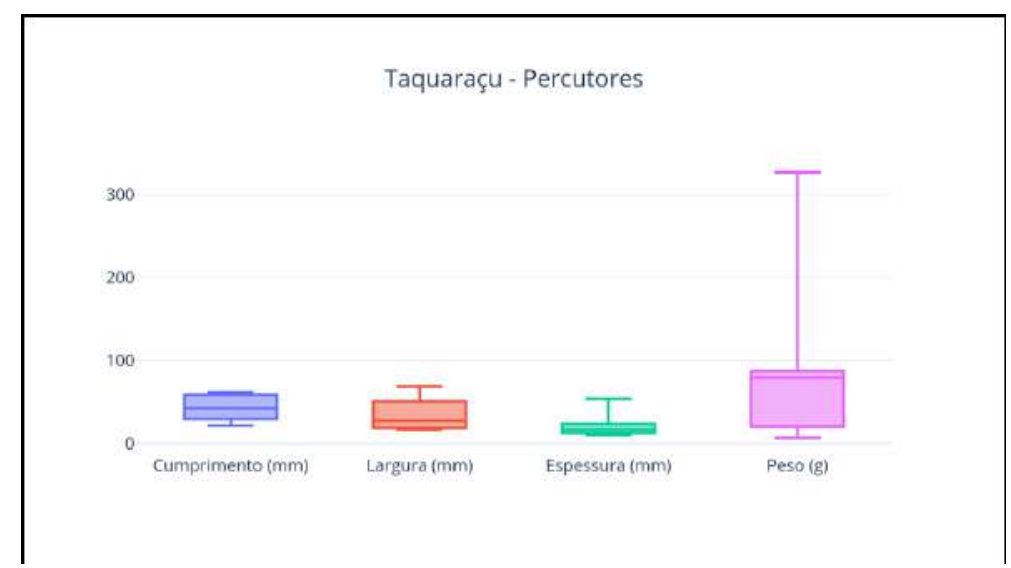

Outros artefatos

É importante destacar que também foram evidenciados no sítio Lapa Grande de Taquaraçu dois artefatos cujas características formais diferem completamente das apresentadas nas demais peças que constituem a sua indústria lítica.

Um deles trata-se de uma peça de silexito retocada unifacialmente e bilateralmente à exaustão, sugerindo um raspador utilizado à exaustão (Figura 6). Esta peça foi encontrada nos níveis mais profundos do sítio, próxima ao solo estéril.

O segundo trata-se de artefato plano-convexo (ou "lesma") manufaturada em quartzito (Figura 7). Assim como a peça anterior, também foi encontrada nos níveis inferiores do sítio. Tal artefato foi descrito em Angeles-Flores et. al. (2016). No artigo mencionado, foi observado que a peça possui características similares às apresentadas pelas lesmas identificadas como pertencentes à Tradição Itaparica. Foi encontrada na Quadra $\mathrm{H8}$, a $90 \mathrm{~cm}$ de profundidade, um pouco abaixo da camada mais antiga, datada em 11.500 cal AP. Desta forma, Angeles-Flores et. al. (2016) consideram que a lesma é mais antiga do que os vestígios líticos da indústria lítica de Lagoa Santa. 


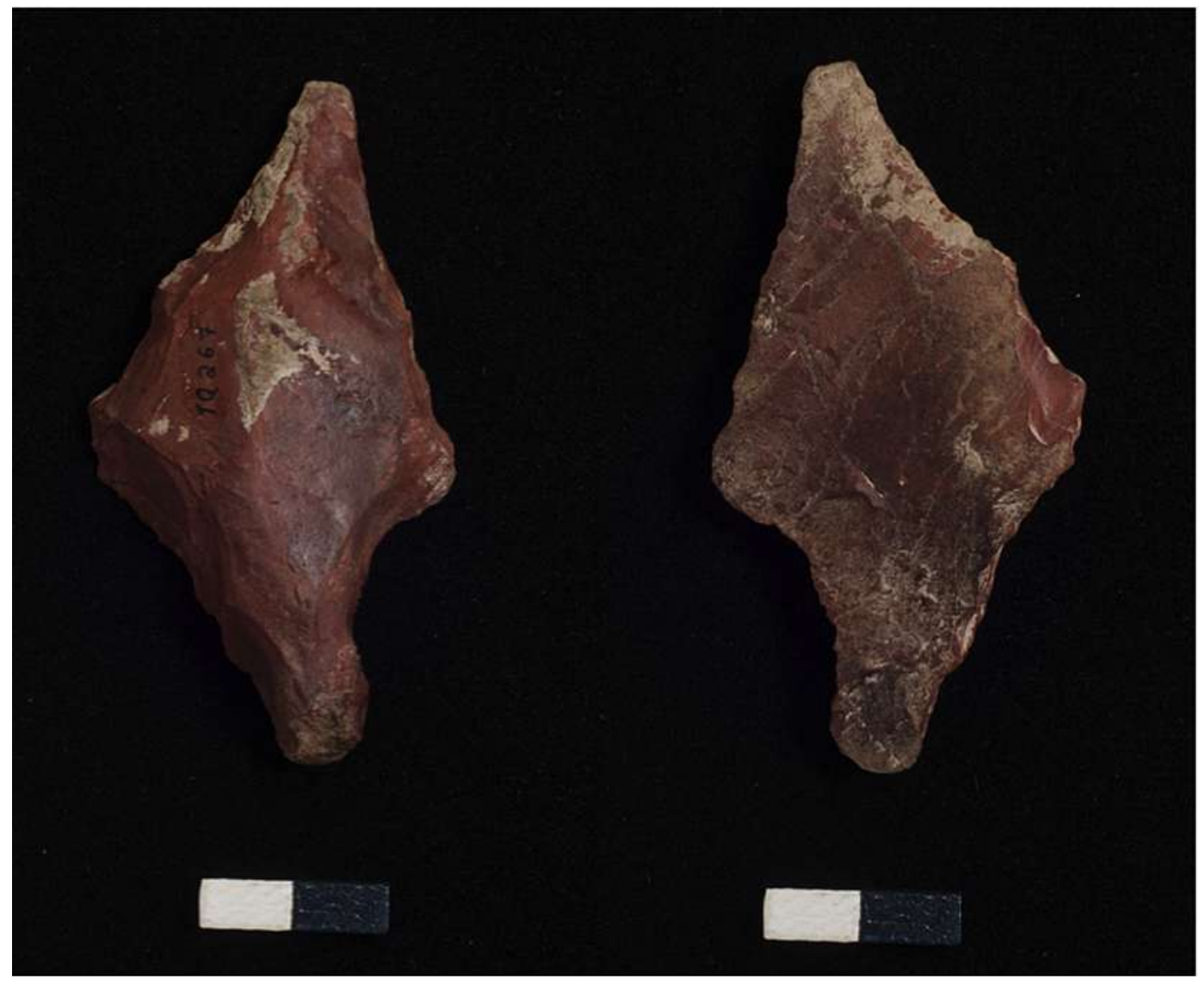

Figura 6: Artefato - sítio Lapa Grande de Taquaraçu (vista frontal). Foto: Ader Gotardo MAE/USP.

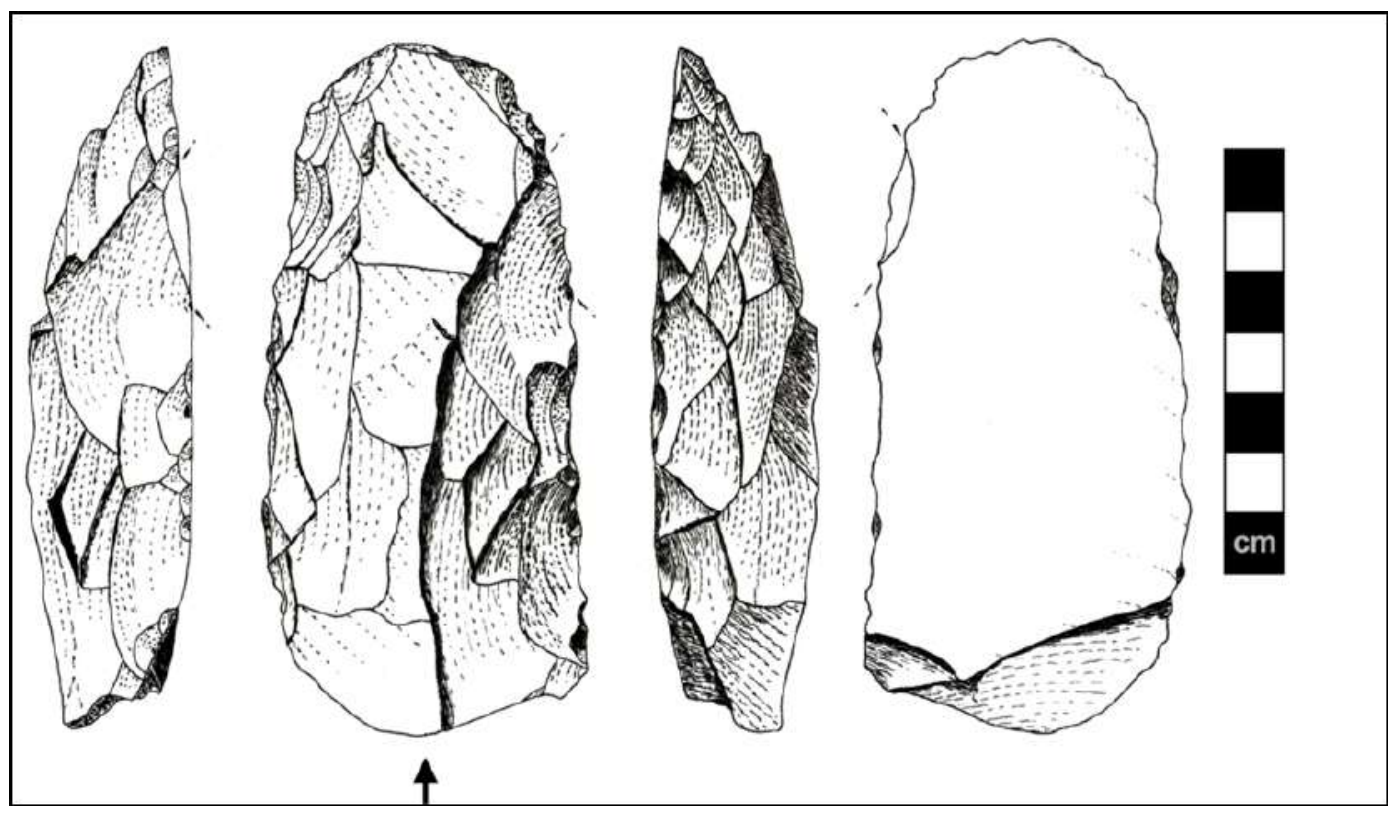

Figura 7: Lesma - sítio Lapa Grande de Taquaraçu. Fonte: Angeles-Flores et al. (2016). 


\section{Discussão}

De modo geral, A indústria lítica do sítio Lapa Grande de Taquaraçu é composta majoritariamente por quartzo hialino (64.7\%) com suporte de cristal. A segunda matéria-prima mais abundante observada foi o quartzo leitoso, seguido de silexito. A maioria dos artefatos cujo suporte foi classificado como indefinido possui como matéria-prima o silexito. Os seixos utilizados são em sua maior parte de quartzo leitoso e todos os blocos são de silexito.

Os núcleos do sítio Lapa Grande de Taquaraçu correspondem a 5.96\% dos artefatos e possuem a tendência de apresentarem dimensões reduzidas, o que é refletido no tamanho das lascas. Todos os núcleos utilizados são de quartzo hialino e correspondem a $0.16 \%$ da amostra.

As lascas configuram a maior parte dos artefatos manufaturados no sítio Lapa Grande de Taquaraçu, seguido das lascas utilizadas. As lascas inteiras não utilizadas representam $59.02 \%$ da amostra e, conforme citado, apresentam dimensões reduzidas, - sem muita variação nos dados - com no máximo $70 \mathrm{~mm}$ de comprimento, $73 \mathrm{~mm}$ de largura e $65 \mathrm{~mm}$ de espessura. As lascas utilizadas, os fragmentos de lasca e as lascas fragmentadas possuem características parecidas com as lascas não utilizadas, porém com frequências menores.

Os fragmentos de lasca utilizada possuem dados de grandeza maiores que os outros artefatos do tipo lasca em geral apresentados anteriormente. Porém estes são bem menos frequentes, representando apenas $0.96 \%$ da amostra. Isso indica que a presença destas lascas maiores pode ser ocasionada simplesmente pela disponibilidade de núcleos maiores.

Em geral, os percutores são constituídos de seixos de quartzo leitoso (46.15\%), seguido de quartzo hialino e quartzo. A maioria destes artefatos possui dimensões reduzidas.

\section{Conclusões}

A indústria lítica do sítio Lapa Grande de Taquaraçu possui características muito parecidas às apresentadas nas indústrias líticas dos sítios Lapa do Santo e Lapa das Boleiras (Araujo et al, 2018; Araujo e Pugliese 2010; Moreno de Sousa e Araujo 2018; Pugliese, 2007).

Observa-se que no sítio Lapa Grande de Taquaraçu há uma grande produção de lascas cujas dimensões reduzidas são decorrentes do tipo de matéria prima escolhida (cristais de quartzo), com ausência de artefatos formais, a despeito de existir uma disponibilidade enorme de outras 
matérias primas de boa qualidade, encontradas na forma de seixos, nas praias do rio, a poucos metros do sítio. Isso reforça as observações feitas por Moreno de Sousa e Araujo (2018) a respeito de um padrão cultural de escolha do quartzo como matéria-prima, não relacionado à proximidade de áreas fonte.

Os dados apresentados corroboram o fato de que o sítio Lapa Grande de Taquaraçu possui características culturais semelhantes às dos sítios associados à Tradição Lagoa Santa. Além do material lítico aqui apresentado, podemos citar a indústria óssea e a fauna explorada (Chim 2018), a acumulação de sedimentos antropogênicos (Araujo, 2008; Araujo e Piló, 2017) e atividades de sepultamento (Araujo et al., 2012). Porém, são necessárias análises tecnológicas comparativas para refinar estas conclusões.

\section{Agradecimentos}

Agradecemos ao Dr. Walter Neves, coordenador do projeto "Origens e Microevolução do Homem na América", pela oportunidade de gerarmos os dados aqui apresentados. À FAPESP e ao CNPq pelo financiamento das etapas de campo (FAPESP 99/00670 e 04/01321-6; CNPq 472535/2007-2), à CAPES por uma bolsa de doutorado (MEV) e ao CNPq pela bolsa de Produtividade em Pesquisa (AGMA, proc. 300339/2008-9).

\section{Referências}

ALKMIN, F.F., MARTINS NETO, A.M. (2001). A bacia intracratônica do São Francisco. Arcabouço estrutural e cenários evolutivos. In: SBG/MG (Org.), Bacia do Sao Francisco: Geologia e Recursos Naturais. Belo Horizonte, p. 9-30.

ANGELES-FLORES, R. (2015). Uso de recursos vegetais em Lapa Grande de Taquaraçu evidencias macro e microscópicas. (Dissertação de Mestrado). Universidade de São Paulo, MAE-USP, São Paulo.

ANGELES-FLORES, R.; SOUSA, J. C. M.; ARAUJO, A.G.M.; CECCANTINI, G. (2016). Before Lagoa Santa: Micro-remain and tecnological analysis in a lithic artifact from the Itaparica industry. Journal of Lithic Studies. v.3, n.1, p. 6-29. Disponível em: http://journals.ed.ac.uk/lithicstudies/. Acesso em: 25 jun 2017.

ARAUJO, A.G.M. (2008). Geoarqueologia em sítios abrigados: processos de formação, estratigrafia e potencial informativo. In: RUBIN, J.C.; SILVA, R.T. (Org.). Geoarqueologia: Teoria e Prática, Editora da PUC Goiás, Goiânia, p. 73-92. 
ARAUJO, A.G.M. (2012). Relatório de Atividades Bolsa de Produtividade CNPq Triênio 2009 / 2012. São Paulo: Museu de Arqueologia e Etnologia.

ARAUJO, A.G.M. (2013). Geomorfologia e paleoambientes no leste da América do Sul: implicações arqueológicas. In: In: RUBIN, J.C.; SILVA, R.T. (Org.). Geoarqueologia. Editora da PUC Goiás, Goiânia, p. 135-180.

ARAUJO, A.G.M. (2015). On vastness and variability: Cultural transmission, historicity, and the Paleoindian record in eastern south America. Anais da Academia Brasileira de Ciências, v. 87, n.2, p. 1239-1258.

ARAUJO, A.G.M.; NEVES, W.A. (2012). A Ocupação Paleoíndia do Sudeste Brasileiro: Lagoa Santa e Além. In: MORALES, W.F.; MOI, F.P. (Eds.) Tempos Ancestrais. Editora Annablume / NEPAB, São Paulo, p. 47-71.

ARAUJO, A.G.M.., NEVES, W.A.; KIPNIS, R. (2012). Lagoa Santa revisited: an overview of the chronology, subsistence, and material culture of paleoindian sites in eastern central Brazil. Latin American Antiquity, 23(4), 533-550. https://doi.org/10.7183/1045-6635.23.4.533

ARAUJO, A.G.M.; PILÓ, L.B. (2017). Towards the development of a tropical geoarchaeology: Lagoa Santa as an emblematic case study. In: DA-GLORIA, P., NEVES, W.A.; HUBBE, M. (Eds.). Archaeological and paleontological research in Lagoa Santa: the quest for the first Americans. Springer International Publishing, p. 373-391.

ARAUJO, A.G.M.; PUGLIESE, F.; OLIVEIRA, R.; OKUMURA, M.M. (2018). Extreme cultural persistence in eastern-central Brazil: the case of Lagoa Santa Paleaeoindians. Anais da Academia Brasileira de Ciências v.90 n.2 Suppl. 1 p. 2501-2521. Disponível em: www.fb.com/aabcjournal.

ARAUJO, A.G.M.; PUGLIESE, F. A. (2010). A indústria lítica. In: ARAUJO, A. G. M.; NEVES, W.A. (Eds.) Lapa das Boleiras: Um Sítio Paleoíndio no Carste de Lagoa Santa. Ed. Annablume / FAPESP, São Paulo, p. 75-105.

BUENO, L. (2012). Entre abrigos e lagoas: tecnologia lítica e territorialidade em Lagoa Santa (Minas Gerais). Revista de Arqueologia/Sociedade de Arqueologia Brasileira, v. 2, n. 5, p. 62-83.

CHIM, E.N. (2018). Zooarqueologia da Lapa Grande de Taquaraçu. (Tese de Doutorado). Universidade de São Paulo, MAE-USP. São Paulo.

DA-GLORIA, P.; NEVES, W. A.; HUBBE, M. (Eds.). (2017). Archaeological and Paleontological Research in Lagoa Santa: The Quest for the First Americans. Springer.

FEATHERS, J.; KIPNIS, R.; PILÓ, L.; ARROYO-KALIN, M.; COBLENTZ, D. (2010). How old is Luzia? Luminescence dating and stratigraphic integrity at Lapa Vermelha, Lagoa Santa, Brazil. Geoarchaeology, v. 25, n.4, p. 395-436.

HOLTEN, B., \& STERLL, M. (2011). Peter Lund e as Grutas com Ossos em Lagoa Santa. Editora UFMG, Belo Horizonte.

KIPNIS, R.; WÜST, I.; DILLEHAY, T.; CHIPPINDALE, C. (1998). Issues in Brazilian archaeology. Antiquity, v. 72, n. 277, p. 571-675. 
MORENO DE SOUSA, J.C.; ARAUJO, A.G.M. (2018). Microliths and Polished Stone Tools during the Pleistocene-Holocene Transition and Early Holocene in South America: The Lagoa Santa Lithic Industry. PaleoAmerica, v. 4, n.3, p. 219-238.

NAKAMURA, C.; MELO J. R.; CECCANTINI, G. T. (2010) Macro-restos vegetais: uma abordagem paleoetnobotânica e paleoambiental. In: ARAUJO, A. G. M.; NEVES, W. A. Lapa das Boleiras: Um Sítio Paleoíndio do Carste de Lagoa Santa, MG, Brasil. Ed. Annablume / FAPESP, São Paulo, p. 159-187.

PROUS, A.; FOGAÇA, E.; RIBEIRO, L. (1998). Patrimônio arqueológico. In: APA Carste de Lagoa Santa - Patrimônio Espeleológico, Histórico e Cultural. Belo Horizonte, CPRM/IBAMA. 22 p., anexos e mapas. Série APA Carste de Lagoa Santa, vol. 3.

PUGLIESE, F. A. (2007). Os líticos de Lagoa Santa um estudo sobre organização tecnológica de caçadores-coletores do Brasil Central. (Dissertação de Mestrado). Universidade de São Paulo, MAE-USP. São Paulo.

SILVA, L. V., \& PROUS, A. P. (2014). O papel dos resíduos de combustão na formação dos estratos sedimentares na Lapa do Niactor: o elemento antrópico como agente dominante na sedimentação em abrigos. Arquivos do Museu de História Natural e Jardim Botânico da UFMG, v. 23, n.2, p. 105-139.

TUDELA, D. R. G. (2013). Caracterização físico-química de sedimentos do sítio arqueológico Lapa Grande de Taquaraçu, MG. (Dissertação de Mestrado). IPEN. São Paulo. 